\title{
Ilmagens contemporâneas do formador do professor de Língua Portuguesa
}

\section{Claudia Rosa Riolfi Émerson de PIETRI Valdir Heitor Barzotto}

Professores de Metodologia do Ensino de Língua Portuguesa da Faculdade de Educação da USP e integram o Grupo de Pesquisas e Estudos e Pesquisa Produção Escrita e Psicanálise - GEPPEP.

Resumo: O presente trabalho visa a investigar a imagem de professor universitário formador do professor de Língua Portuguesa que pode ser depreendida de editais de concursos para ingresso na carreira docente, em cursos de Licenciatura em Letras de Universidades públicas brasileiras. Tomamos como objeto de análise dois editais de concursos, publicados em 2007, que regulamentaram as ações de ingresso na carreira docente de universidades públicas, uma localizada na Região Centro-Oeste e outra na região Sul. Buscamos responder a duas questões: a) O que significa explicitar a palavra "ensino" em um programa de concurso?; e b) O que significa explicitar o nome de uma disciplina em um programa de concurso? Concluímos que diferentes sentidos - produzidos em relaçōes caracterizadas pela consonância, dissonância, ou mesmo pela contraposição - podem ser atribuídos ao formador, num determinado momento histórico.

Palavras-chave: Imaginário; formação de professores; editais de concurso
Abstract. This work aims to investigate the image of university professor responsible for Portuguese teacher's formation. Two Official programs (tender announcements) for the position of university professor, published in 2007, by two different Brazilian public universities, were analyzed. Requirements for university career were observed in order to answer to two research questions: a) what does it mean to explicit the word "teaching" in a Official program?; and b) what does it mean to explicit a discipline's name in a tender document? The conclusion is that different meanings produced in the relations characterized by consonance, dissonance, or even opposition - may be attributed to professors responsible for Portuguese teacher's formation in a particular historical moment.

Key-words: Imaginary; teacher's formation; Official programs

O presente trabalho é um dos resultados do projeto "Representaçōes concernentes à formação do professor de língua materna: Estudos sobre a especificidade da disciplina "metodologia/didática/prática do ensino da Língua Materna", apoiado pela Pró-reitoria de pesquisa da Universidade de São Paulo. Parte de um projeto mais amplo, do qual fazem parte também os professores Claudemir Belintane, Idméa Semeghini-Siqueira e Neide Luzia de Rezende, seu objetivo é circunscrever quais são as especificidades atuais do campo recoberto pelas práticas e saberes mobilizados nas disciplinas que se encarregam diretamente de conteúdos relacionados ao ensino e aprendizagem da Língua Portuguesa nos cursos de Letras do Brasil, oferecendo, consequentemente, contribuiçōes para a formação de professores universitários. 



\section{Introdução}

A diversidade de práticas de formação de professores de Língua Portuguesa institucionalizadas no Brasil, em sua relação com os modos de organização dos atuais currículos dos cursos de Licenciatura em Letras, está diretamente relacionada com as questões colocadas pela ampla heterogeneidade que se encontra no ensino de Língua Portuguesa no ensino fundamental e médio.

Antes que se possa considerá-la positiva ou negativamente, a heterogeneidade é um elemento que, analisado, pode oferecer dados importantes sobre o atual processo de formação de professores, e contribuir, nesse sentido, para a compreensão das diferentes imagens do que seja o formador do professor de Língua Portuguesa.

Decorrentedeum processohistórico complexo, que envolve relações tensas entre produção do conhecimento em instâncias acadêmicas e políticas educacionais, estabelecidas por projetos de Estado e ações de governos, a ordem atual em que se insere a formação do professor de língua portuguesa, no Brasil, oferece elementos importantes para a compreensão das relações conflituosas entre heterogeneidade sóciocultural e projetos nacionais de unificação linguística.

Associada a um processo de democratização do ensino institucionalizado, realizado sem preocupações com questões de qualidade ou com as relações entre grupos sociais específicos e o projeto de escola a eles oferecido, a formação de professores no país tem se realizado em função das demandas do mercado de trabalho por mão de obra especializada.

Nesse contexto, as discussões sobre ensino de língua portuguesa congregam elementos advindos de questões sociais e políticas mais amplas a saberes específicos sobre Língua Portuguesa produzidos na Universidade: o resultado desse processo é uma grande diversidade de concepções de linguagem e de ensino coocorrendo e concorrendo para a formação de professores - e um conflito constantemente retroalimentado pelas polêmicas, atualizadas nas práticas escolares, em 
produções acadêmicas, e nos documentos oficiais sobre ensino de língua portuguesa, entre novas e antigas concepções de linguagem e de ensino.

A resultante institucional desse processo, para a formação de professores, pode ser vista na heterogeneidade que se observa no campo recoberto pelas disciplinas que, em cursos universitários que formam professores, se encarregam diretamente de sua preparação para o ensino de língua portuguesa no país. Essa heteiugeneidade se encontra nos modos de organização das próprias disciplinas, em relação aos objetivos estabelecidos pelo professor-formador por ela responsável, que podem se caracterizar pela divulgação da situação do ensino de língua portuguesa no país com base em pesquisas realizadas nas universidades ou por órgãos de governo; pela divulgação de determinadas perspectivas teóricas com as quais o responsável pela disciplina tem afinidade e considera suficientes para ser utilizadas no tratamento de questões de ensino; ou ainda pela leitura de documentos sobre ensino (oficiais ou acadêmicos), muitas vezes apenas de modo a realimentar polêmicas já estabelecidas. Como exemplo dessas polêmicas frequentemente atualizadas destacam-se as que se fundamentam em enunciados que relacionam a dificuldade dos brasileiros para a aprendizagem da leitura e da escrita à baixa qualidade do ensino, ou à falta de acesso a bens culturais devido à sua baixa renda; ou em enunciados que associam os problemas no ensino de português ao fato de os professores não seguirem a linha teórica defendida por aquele que toma a situação como objeto de análise, seja o pesquisador, seja o professor formador, responsável pelos componentes curriculares relativos à prática de ensino que usa o texto do pesquisador em suas aulas.

A heterogeneidade característica dos modos de organização das disciplinas em relação a seus objetivos mostra-se também nos modos de inserção institucional dessas disciplinas nos currículos dos cursos de Licenciatura. Assim, a consideração das especificidades conferidas a 
essas disciplinas, tanto em relação a suas denominações (Metodologia, Prática, Didática, Fundamentos do Ensino de Língua Portuguesa), conteúdos e objetivos, quanto em relação aos loci institucionais em que se encontram inseridas (se na Faculdade de Letras ou na de Educação, por exemplo), pode oferecer elementos importantes para a compreensão das concepções de linguagem e de ensino que têm fundamentado as decisões sobre a formação do professor de Língua Portuguesa.

Uma vez que essas decisões se apresentam no momento em que se estabelece o próprio perfil do docente responsável pela formação do professor de língua portuguesa, visamos, no presente trabalho, a investigar que imagem de professor universitário formador do professor de Língua Portuguesa está indiciadas nos editais de concursos para ingresso na carreira docente, em cursos de Licenciatura em Letras de universidades públicas brasileiras.

Trata-se, assim, de verificar como a práxis do docente que se ocupa da formação de futuros professores tem sido entendida pelas instituições responsáveis por essa formação, em especial no que tange à atividade de orientação de estágios supervisionados, atividade esta prevista por lei nos currículos das licenciaturas em Letras.

\section{A problemática estudada e as bases teóricas da análise}

A nosso ver, a mobilização de saberes na disciplina começa a se delinear nas próprias exigências constantes nos editais de concursos para contratação de professores pelas universidades. Assim sendo, nossa hipótese é a de que se pode depreender - por meio da formação e dos conhecimentos que são exigidos do candidato, bem como da descrição das funções que serão atribuídas ao docente que vier a assumir a vaga - a imagem de docente que as universidades estão buscando, e, consequentemente, a do professor de língua portuguesa do ensino fundamental e médio. Consideramos que o esforço de tomar 
1 No esquema proposto por Jakobson, cada uma das letras representava um dos pólos da linguagem em uso, da seguinte maneira: " $A$ " o destinador; " $B$ " o destinatário; " $\mathrm{R}$ " o referente, "(L)". o ; código lingüístico comum entre $\mathrm{A} \mathrm{e}$ B; "D" a seqüência verbal emitida por A em direção a B, e, finalmente, a flecha indicava o contato estabelecido entre " $\mathrm{A}$ " e "B". editais de concurso como objeto de análise se justifica principalmente por partirmos do pressuposto de que sua leitura pode dar a ver como, no Brasil, tem se constituído, na contemporaneidade, a formação universitária do professor de língua materna.

Nosso ponto de partida, portanto, foram dois editais de concursos, publicados em 2007, que regulamentaram as ações de ingresso na carreira docente de universidades públicas, uma localizada na região Centro-Oeste e outra na região Sul. Cada um deles apresenta elementos específicos que nos servem para delinear uma mesma questão. No desenvolvimento da pesquisa, faremos análise ou referência a outros editais que permitem ampliar as discussões a respeito da problemática delineada nos dois subitens que se seguem.

Tendo como objetivo analisar os modos de elaboração do perfil do formador de professores, em editais de concurso de contratação, tornou-se imperativo o acréscimo de categorias analíticas derivadas da noção de "imagem" proposta por Pêcheux (1990), e de questões similares àquela feita por Foucault (1987) sobre a descrição de acontecimentos do discurso: "como apareceu um determinado enunciado, e não outro em seu lugar?"

Quando se analisa uma produção textual qualquer, uma pergunta costumeiramente feita incide sobre os motivos que teriam determinado a ocorrência de temas, argumentos, arranjos linguísticos etc. Por que apareceu este assunto e não outro? Por que este texto foi escrito deste modo e não de outro? São interrogações legítimas que despertam a curiosidade do estudioso da linguagem e clamam pela construção de respostas.

Visando a construir uma resposta para elas, ao fazer uma releitura dos elementos estruturais pertencentes às condições de produção do discurso, em primeiro lugar, Pêcheux privilegia o esquema informacional, previamente estabelecido por Jakobson (1963, apud PÊCHEUX, 1990), que, reproduzimos na sequência: ${ }^{1}$ 


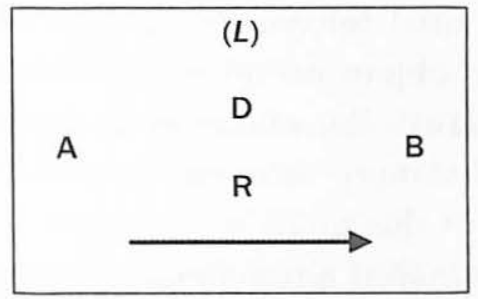

Ao analisar o esquema proposto por Jakobson, Pêcheux frisa que, tal qual foi estabelecido, ele gerava uma compreensão de que "D" equivalia a uma mensagem, entendida como transmissão de informação. Por acreditar em uma concepção de linguagem na qual existem discursos que determinam os textos que são efetivamente realizados, ele propôs que à concepção de transmissão de informação, fosse dada preferência à de "efeito de sentidos" (p.82).

Como consequência desse deslocamento teórico, Pêcheux viu-se impelido, então, a repensar a natureza de "A" e de "B" no esquema informacional. Longe de pensar que estas letras sinalizavam a presença física de seres humanos, o autor passou a postular que elas apontavam para "lugares determinados na estrutura de uma formação social" (p.82) e, na seqüência, explicitou o modo como passou a pensar para analisar uma sequência verbal qualquer. Em suas palavras: "Nossa hipótese é a de que esses lugares estão representados nos processos discursivos em que são colocados em jogo". (p.82).

Refinando esta construção, o autor esclareceu, ainda, que, na teoria que vinha construindo, não se tratava da possibilidade de que o lugar (por exemplo, o de patrão, ou o de professor) funcionasse como tal no processo discursivo. Para Pêcheux, o lugar se encontra presente, mas transformado, ou, "em outros termos, o que funciona nos processos discursivos é uma série de formações imaginárias que designam o lugar que A e B se atribuem cada um a si e ao outro, a imagem que eles fazem do seu próprio lugar e do lugar do outro" (p.82).

Posto isso, Pêcheux esclareceu que todo processo discursivo supõe a existência de formações imaginárias. Essa generalização, por sua vez, redefine a noção de 
"referente" tal qual foi construída por Jakobson. Longe de referir a um objeto no mundo, passou a designar um "objeto imaginário". Por este motivo, Pêcheux afirma que "a percepção é sempre atravessada pelo "já ouvido" e o "já dito", através dos quais se constitui a substância das formações imaginárias enunciadas” (pp.85-6).

Tendo em vista o que acabamos de expor, vamos em busca da manifestação de uma imagem de formador em editais de concurso.

\section{Constituição do corpus de análise e produção dos dados}

\subsection{O que significa explicitar a palavra "ensino" em um programa de concurso?}

$\mathrm{Na}$ Universidade localizada na região CentroOeste do país, foram abertas e publicadas, em um mesmo Edital, duas vagas, uma para Língua Portuguesa e outra para Literatura. $\mathrm{O}$ requisito exigido para a primeira era 'graduação em Letras com Mestrado em Letras - Áreas conexas: Linguística, Língua Portuguesa’.

O candidato a esta vaga deveria demonstrar conhecimento a respeito do programa que consta no Quadro A, que se segue:

\section{PROGRAMA 1}

ÁREA DE CONHECIMENTO: Língua Portuguesa SUBÁREA: Língua Portuguesa

1. Sintaxe e gramática escolar.

2. Fonética e Fonologia.

3. Princípios Básicos da Análise Mórfica.

4. Português do Brasil: variação e mudança linguística.

5. Aspectos diacrônicos da Língua Portuguesa.

6. Gramática Tradicional: fundamentos e críticas.

7. Aspectos semânticos.

8. Estilística da Língua Portuguesa.

9. O ensino de leitura e de produção textual.

10. Coesão e coerência textuais.

11. Linguística e ensino da língua.

12. Concepções de texto.

13. A prática de análise linguística. 
14. As relações entre texto e discurso.

15. Tipologias e gêneros textuais.

Quadro A: Programa de concurso em Língua Portuguesa em Universidade localizada na região Centro-Oeste do país

Por sua vez, o requisito para a inscrição de um candidato que se propusesse a concorrer à segunda vaga (a de Literatura) era "graduação em Letras com mestrado na área de Literatura”. O candidato interessado em obter aprovação para esta vaga deveria demonstrar conhecimento a respeito do Programa do concurso que consta no Quadro B, na sequência:

\section{PROGRAMA 2}

ÁREA DE CONHECIMENTO: L.́ngua Portuguesa SUBÁREA: Literatura

1. O cânone literário brasileiro.

2. Aspectos da Lírica moderna.

3. Literatura e História: interfaces.

4. Elementos estruturais da narrativa.

5. Literatura, Estudos Culturais e Pós-modernismo;

6. A poética de Cláudio Manuel da Costa e o Arcadismo brasileiro.

7. A tradição regionalista na literatura brasileira.

8. A ficção realista de Machado de Assis.

9. Sousândrade e a diversidade na poesia romântica brasileira.

10. Lima Barreto e o Pré-Modernismo.

11. A poética de Manoel Bandeira - entre a tradição e o popular.

12. A prosa de Guimarães Rosa.

13. Manoel de Barros e a literatura sul-mato-grossense.

Quadro B: Programa de concurso em Literatura em Universidade localizada na região Centro-Oeste do país

Da leitura do Edital na íntegra destacamos especialmente o item 2.2, constante no tópico " $D A S$ VAGAS E UNIDADE UNIVERSITARIA": 
O candidato aprovado em Literatura poderá, de acordo com a necessidade, ser lotado nas disciplinas de Introdução à Metodologia Científica, Técnicas em Redação e Estágio Supervisionado.

Cotejando este item com os dois programas constantes do mesmo edital, chama a atenção que o profissional absorvido para a vaga de Literatura poderá assumir a orientação das atividades de estágio supervisionado, ainda que não conste do programa do concurso nenhum item que solicita ao candidato alguma demonstração de conhecimento relacionado a questões de ensino.

Por sua vez, ainda que no programa exigido para Língua Portuguesa constem três itens que mencionam explicitamente a relação com o ensino, não está previsto no Edital que o profissional absorvido possa vir a assumir o Estágio Supervisionado.

O primeiro item do programa (O cânone literário brasileiro) localiza o candidato. A vaga foi aberta para "Literatura", sem qualquer especificação de que literatura se trata (brasileira, portuguesa, latina etc.).

Ele versa a respeito de autores considerados representativos de diferentes escolas literárias, não exigindo uma cultura geral a respeito da produção realizada em nosso país. Não consta nenhum item que verse a respeito do ensino de Língua Portuguesa ou de sua literatura.

A bibliografia proposta é composta por quarenta e oito livros, em sua maioria oriundos do campo da teoria e crítica literária, mais exatamente, trinta e sete volumes. Os outros onze volumes tratam mais especificamente da literatura brasileira.

Sem entrar em questão a respeito da qualidade do programa, o que não é o objetivo deste trabalho, podemos, agora, abordar o dado de modo mais relacionado à especificidade de nosso trabalho.

Não consta qualquer indicação bibliográfica que verse a respeito do ensino da literatura, da formação do 
leitor, do ensino de leitura ou qualquer outro assunto que pudesse estar direta ou indiretamente ligado ao ensino de Língua Portuguesa.

No mesmo concurso, a vaga para Língua Portuguesa, que não indicava a possibilidade de o docente poder lecionar estágio, continha, no entanto, itens no programa e na bibliografia mais próximos ao ensino que o de Literatura.

Então, tocamos na heterogeneidade e podemos vislumbrar movimento em direções diferentes na constituição da imagem do formador e do professor: em uma direção, o programa de Literatura parece indicar que para a instância elaboradora do programa basta o domínio de um conteúdo específico para que alguém possa formar um professor e, depois, para trabalhar com a língua e a literatura na escola básica; em outra direção, o programa de Língua Portuguesa dá a entender que, por se tratar de um curso de formação de professores, todas as matérias precisam passar por algum conteúdo que relacione os conteúdos da disciplina com o ensino.

\section{2. O que significa explicitar o nome de uma disciplina em um programa de concurso?}

$\mathrm{Na}$ Universidade localizada no Sul do país, abriram-se também duas vagas. A primeira, para Linguística e Língua Portuguesa, apresentava como exigência "Graduação em Letras (licenciatura plena) com Mestrado em Linguística ou Língua Portuguesa e 1 (um) ano de experiência no Ensino Superior". A segunda, para Prática de Ensino de Língua Portuguesa e Literatura, exigia "Graduação em Letras (licenciatura plena) com Mestrado em Letras, Linguística, Língua Portuguesa ou Literatura, e 1 (um) ano de experiência no Ensino Superior".

Observemos os dois programas, transcritos no Quadro C, que se segue: 


\begin{tabular}{|c|c|}
\hline PROGRAMA 3 & PROGRAMA 4 \\
\hline $\begin{array}{c}\text { Área/Subárea: Linguística } \\
\text { e Ĺngua Portuguesa }\end{array}$ & $\begin{array}{l}\text { Área/Subárea: Prática de Ensino } \\
\text { de Ĺngua Portuguesa e Literatura }\end{array}$ \\
\hline ITENS DO CONTEÚDO & ITENS DO CONTEÚDO \\
\hline PROGRAMÁTICO: & PROGRAMÁTICO: \\
\hline $\begin{array}{l}\text { 1. Concepções de } \\
\text { língua/linguagem e ensino }\end{array}$ & $\begin{array}{l}\text { 1. Literatura, história } \\
\text { e sociedade }\end{array}$ \\
\hline $\begin{array}{l}\text { 2. Concepções de gramática } \\
\text { e ensino }\end{array}$ & $\begin{array}{l}\text { 2. Concepções de gramática } \\
\text { e ensino }\end{array}$ \\
\hline $\begin{array}{l}\text { 3. Variedade linguística } \\
\text { e ensino }\end{array}$ & 3. Texto, discurso e ensino \\
\hline $\begin{array}{l}\text { 4. Gêneros textuais/discursivos } \\
\text { e ensino }\end{array}$ & $\begin{array}{l}\text { 4. PCNs e ensino de língua } \\
\text { portuguesa e literatura }\end{array}$ \\
\hline 5. Análise textual/discursiva & $\begin{array}{l}\text { 5. Concepções de leitura e } \\
\text { ensino de língua portuguesa } \\
\text { e literatura }\end{array}$ \\
\hline $\begin{array}{l}\text { 6. Variedade padrão e ensino } \\
\text { reflexivo }\end{array}$ & $\begin{array}{l}\text { 6. Teoria sóciointeracionista } \\
\text { e ensino de linguagem }\end{array}$ \\
\hline $\begin{array}{l}\text { 7. Concepções de leitura e } \\
\text { ensino }\end{array}$ & $\begin{array}{l}\text { 7. Língua e literatura: } \\
\text { perspectivas sócio-históricas }\end{array}$ \\
\hline 8. Sintaxe da língua portuguesa & $\begin{array}{l}\text { 8. Ensino de língua e } \\
\text { literatura nos materiais } \\
\text { didáticos }\end{array}$ \\
\hline $\begin{array}{l}\text { 9. Relação entre } \\
\text { oralidade/escrita e ensino }\end{array}$ & $\begin{array}{l}\text { 9. Interdisciplinaridade no } \\
\text { ensino de língua portuguesa } \\
\text { e literatura }\end{array}$ \\
\hline $\begin{array}{l}\text { 10. Tendências linguísticas do } \\
\text { século } \mathrm{XX}\end{array}$ & $\begin{array}{l}\text { 10. Metodologia no ensino de } \\
\text { língua portuguesa e literatura }\end{array}$ \\
\hline $\begin{array}{l}\text { Observação: O candidato } \\
\text { deverá, também, fazer uma } \\
\text { abordagem metodológica do } \\
\text { tema sorteado para a prova escrita. }\end{array}$ & $\begin{array}{l}\text { Observação: O candidato } \\
\text { deverá, também, fazer uma } \\
\text { abordagem metodológica do } \\
\text { tema sorteado para a prova escrita. }\end{array}$ \\
\hline Quadro C: Prog & $\begin{array}{l}\text { em Universidade localizada na } \\
\text { do país }\end{array}$ \\
\hline
\end{tabular}

Note-se a presença da palavra "ensino", adicionada a praticamente todos os tópicos do Programa 3, exigido para a vaga de Linguística e Língua Portuguesa. Note- 
se também que, diferentemente da Universidade localizada na região Centro-Oeste, este edital não indica a possibilidade de o docente poder atuar em estágio supervisionado. No entanto, em função justamente da palavra ensino e da observação constante logo abaixo do programa, o candidato pode inferir que tal atuação lhe será solicitada.

Com relação ao Programa 4, para a vaga específica para a disciplina Prática de Ensino de Língua Portuguesa e Literatura, destaca-se que ele propõe tópicos em que língua, literatura e ensino aparecem de forma mais articulada do que pela adição da palavra "ensino" aos pontos do programa, como é o caso do Programa 3.

No entanto, a formação exigida para o candidato para a vaga de Prática de Ensino de Língua Portuguesa $e$ Literatura difere da primeira apenas pelo acréscimo da formação em literatura, uma vez que "mestrado em letras” geralmente abarca Língua Portuguesa, Linguística e Literatura.

Com a exposição feita a respeito de dois editais de concursos recentes, realizados em universidades públicas brasileiras, neste ponto de nosso trabalho, estamos, então, em condições para elaborar uma primeira hipótese a respeito da imagem da práxis do docente que se ocupa da disciplina encarregada da articulação entre os conhecimentos fornecidos no curso e a prática de ensino na formação de futuros professores em cursos de Letras nas universidades públicas de nosso país.

Nossa hipótese tem como pano de fundo uma questão linguística propriamente dita, uma vez que considera a presença de um significante qualquer $\square$ no caso, a palavra "ensino" e os títulos das disciplinas [ como sendo indício de uma formulação prévia, por parte do corpo dirigente de uma universidade pública, de um departamento, ou de uma área, de um perfil de profissional desejável para se encarregar das disciplinas diretamente relacionadas com a parte mais prática da formação do professor de Língua Portuguesa. 
Estamospartindodopressupostodequedocumentos com a força institucional de um edital de concurso, ao serem publicados e colocados em circulação, produzem uma determinada imagem de práxis profissional, que, constituída na cultura, tem potencial para ajudar a definir o que deve ou não ser feito na formação do profissional em Letras que vai assumir uma sala de aula e trabalhar com o ensino de Língua Portuguesa.

Os programas deste concurso acrescem aos anteriores a convicção de que, em cursos que não têm bacharelado, algumas disciplinas que, pelo menos em termos de conteúdo, não teriam necessariamente de se preocupar com o ensino, o fazem em função do profissional que se pretende formar.

\section{Análise dos dados}

Elementos como os que acabamos de expor podem ser analisados a partir das formações imaginárias propostas por Pêcheux. Trata-se de considerar que o edital é uma projeção, calcada no imaginário, de "um feixe de traços objetivos característicos" do que se delineou no interior da instituição sobre o que seja o professor formador. Ao mesmo tempo, ele ancora uma antecipação de uma imagem. É porque, de algum modo, se pressupõe no interior das instituições quais seriam as imagens de professor e de seu formador que estariam já constituídas na sociedade contemporânea e delineadas nas formações imaginárias em funcionamento, que se procura pelos editais antecipar esta imagem. Assim, os programas publicados nos editais respondem a esta imagem, buscando oferecer tal imagem como resposta ao que, na Universidade, se supõe saber que se espera dela.

Desse modo, o texto do edital, em especial o programa, que, até ser publicado, passou por um processo que procurou conferir aparência de regularidade e objetividade para a situação dos elementos que compõem a formação de um professor, apresenta o funcionamento de um conjunto de formações imaginárias que designam os lugares que os participantes de sua confecção 
atribuem a si mesmos e que "imaginam" deva ser aquele do "candidato".

Decorrem daí objetivos para pesquisas que procurem ter acesso ao imaginário do que seja o professor formador e daqueles que serão por ele formados, e a que em parte procuramos responder com nosso trabalho: verificar qual é e como é construída esta aparente regularidade.

Algo de interessante (preocupante talvez) que move a necessidade de uma pesquisa como esta é nossa pressuposição de que é necessário dar uma outra resposta, estabelecendo os contornos de um outro lugar, a esta mesma sociedade contemporânea, que de algum modo já se ressente justamente do esvaziamento dos contornos. Ao olharmos para os editais, embora possamos deslindar alguns traços componentes deste perfil, delineados para responder a demandas oriundas de diferentes instâncias, percebemos também com que fragilidade tais traços se juntam, de modo a compor um perfil fluido, quase indelével.

A volatilidade dos perfis em questão se evidencia nos modos de elaboração dos editais de concurso em análise: o Programa 1 responde às representações de que um curso de Letras que não tem a habilitação para o bacharelado é um curso exclusivo de formação de professores. Há, porém, um processo de ajustamento, em que as mudanças a serem realizadas nos cursos se pautam pela imagem do que seja um curso de Letras estruturado com base na formação do bacharel e do licenciado, tomando o bacharelado como a base da formação profissional. Decorre daí que a disciplina de Língua Portuguesa - de cujo candidato possivelmente se vai exigir que assuma estágio, embora isso não esteja explícito no edital - tenha também de relacionar alguns itens do conteúdo específico, próprios ao bacharelado, a questões relacionadas ao ensino.

O mesmo processo pode ser observado no Programa 2, para a disciplina Literatura, do mesmo edital, em que não se apresenta nenhuma relação entre conteúdos específicos e questões relacionadas ao ensino, mas se atribui ao titular da disciplina a tarefa 
de orientar atividades de estágio. Tomando a formação do bacharel como base para as demais atividades do profissional em Letras, a elaboração do edital responde a uma representação de que basta ao professor acesso a um conhecimento específico sólido para que se esteja habilitado a trabalhar com questões de ensino.

Além disso, é preciso considerar também que, embora se trate de um mesmo edital, de uma mesma Universidade, os grupos que definem os programas são diferentes. Portanto, o mesmo edital responde a demandas institucionais de lugares diferentes, a imagens diferentes.

Outro fator a se considerar é o de que as demandas evidenciam lugares e sujeitos que atuam na cena sem que necessariamente sua presença se faça de modo explícito; ou seja, os programas, ao delinear o perfil do formador procurado, põem em funcionamento imagens oriundas de outras instâncias — como, por exemplo, Secretarias de Estado - e de grupos de pesquisadores que fazem circular mais hegemonicamente suas convicções e mantêm relação de maior proximidade com os agentes políticos que ocupam os lugares de poder decisório num determinado momento histórico, como aquele em que o edital foi elaborado.

Tais formações, em funcionamento, caracterizam o perfil do formador a partir da imagem feita por um sujeito que agencia a voz da instituição (a Universidade) para a qual seria contratado o professor formador. Esta voz, aglomerando decisões de um departamento, organiza um conjunto de traços oriundos de outras instâncias, que confere os contornos do referente: a imagem do profissional a ser contratado e de sua prática - e, em consequência, do professor a ser formado.

A força institucional do que está expresso no edital põe em jogo posições que o candidato deveria ocupar para ser aceito e considerado adequado a se responsabilizar pelas funções a ele atribuídas.

Nessas condições, diferentes sentidos podem ser atribuídos ao formador, num determinado momento histórico. Tais sentidos podem se apresentar em relações 
caracterizadas pela consonância, dissonância, ou mesmo pela contraposição. Os editais analisados mostram que essas relações se materializam nos textos produzidos para a definição do perfil do profissional a ser contratado nas instituições formadoras de professores.

As assonâncias, dissonâncias ou contraposições presentes nos editais evidenciam a fluidez do perfil do formador, a que se fez referência anteriormente. Aquilo a que se referiu como volatilidade dos perfis parece ser efeito desse conjunto de vozes que se aglomeram institucionalmente no momento em que os editais são elaborados. Dadas as diferentes forças que atuam sobre os sentidos, em função dos valores históricos, sociais e políticos distintos que compõem o quadro em que os enunciados se materializam, parece se tornar impossível a constituição de um vetor que direcione a enunciação.

A hipótese com que se trabalha é que as assonâncias, dissonâncias e contraposições compõem de tal modo as vozes institucionais e seus conjuntos de forças, nos momentos de definição do perfil dos formadores, que as formações imaginárias não podem assumir a estabilidade que, na proposta de Pêcheux (1990), se evidenciaria; isto é: a série de formações imaginárias não designariam, no caso em estudo, lugares estáveis que A e B atribuiriam a si mesmos e ao seu outro, mas se fariam de modo fluido, instável.

\section{Considerações finais}

Os dados produzidos a partir de editais de concurso para contratação de docentes responsáveis pela formação inicial de professores de Língua Portuguesa, e a análise desses dados, com base nas contribuições teóricas elaboradas no interior da análise do discurso, evidenciam a necessidade de se tomar como objeto de estudos a constituição do perfil desse profissional em seus aspectos institucionais mais amplos.

O que a análise parece ter demonstrado é que não é possível considerar que a função do formador de professores se defina e se estabilize em relação a um conjunto de forças que determinam a estruturação dos currículos dos cursos 
de Licenciatura em Letras. Se essa estabilidade talvez possa ser observada em relação aos conteúdos específicos, principalmente os que se referem à formação do bacharel, conhecedor da literatura e sua teoria, ou das estruturas e funcionamentos das línguas em que se habilita, o mesmo não pode ser observado em relação à formação do professor de Língua Portuguesa como língua materna.

Nesse caso, mesmo a relação entre a formação do licenciado e os conteúdos específicos do bacharel, supostamente mais estabilizados, pode ser fator de desestabilização das funções atribuídas ao professor formador e, em consequência, ao profissional a ser licenciado.

Esses resultados apresentam a necessidade de continuação dos estudos que têm por objeto os fatores institucionais envolvidos na formação do professor de Língua Portuguesa. Nesse sentido, é necessário obter mais dados a respeito dos modos de inserção do formador nas instituições formadoras e, consequentemente, na estrutura curricular dos cursos de Letras, e, assim, obter também dados sobre o funcionamento das disciplinas de formação de professores e os modos como os responsáveis por essas disciplinas conduzem suas ações.

Se, neste momento, iniciamos a análise dos modos como se constituem os perfis dos professores formadores a serem contratados pelas universidades - pesquisa que, como afirmado, se encontra em seus momentos iniciais e necessita de prosseguimento para obtenção de mais dados - num segundo momento, é preciso obter dados a respeito dos professores de fato contratados com base nos editais de concurso analisados, a fim de buscar compreender as relações que se estabelecem entre o perfil de formador que se elabora institucionalmente e se materializa textualmente nos editais, e o perfil do professor contratado. Essa análise pode fornecer elementos para a compreensão das leituras realizadas dos textos produzidos institucionalmente, e das relações de força estabelecidas no momento em que se define qual professor, dentre os habilitados a concorrer à função, é considerado apto a se posicionar no lugar de formador. 


\section{Reíerências}

FOUCAULT. Michel - Arqueologia do saber. São Paulo:

Forense, 1987.

PÊCHEUX, Michel. Análise automática do discurso (AAD-69). In: GADET, F. \& HAK, T. (orgs). Por uma análise automática do discurso. Uma introdução à obra de Michel Pêcheux. Campinas: Editora da Unicamp, 1990. In: Pp. 61-161. 